\title{
RELIABILITY-BASED INTEGRATED DESIGN APPROACH FOR PLANAR STEEL FRAMES
}

\author{
Yu-Shu Liu* and Guo-Qiang Li \\ School of Civil Engineering, Tongji University, Shanghai, China \\ *(Corresponding author: E-mail: ysliu@mail.tongji.edu.cn)
}

\begin{abstract}
The current design method of steel structures is based on the member reliability and cannot assure the structural system reliability. To overcome the shortcoming of the current method, the integrated structural design approach, with consideration of system reliability for planar steel frames, is studied in this paper. The reliability-based integrated design approach (RID) directly checks the structural system limit states, based on structural nonlinear analysis, and the corresponding system reliability. In this paper, the reliability-based integrated design approach for planar steel frames is established on the basis of evaluating the ultimate load-carrying capacity and system reliability of planar steel frames. In the process of constructing the design formula, the target reliability index and importance factor are determined according to the current specification and the two common load combinations are considered. Design examples and comparisons demonstrate that RID provides a feasible way for structural engineers to improve the design quality of steel frame structures with certain and consistent system reliability levels.
\end{abstract}

Keywords: Reliability-based integrated design; Planar steel frames; Member reliability; System reliability; Target reliability index.

\section{INTRODUCTION}

As we all know, the system reliability of a structure is not only related to structural member reliability, but also influenced by the correlation between the members, the correlation between resistance and load, the configuration of the structure, the structural redundancy and ductility [1]. Actually, a building structure fulfills its function as an integrity, and a designer should aim at ensuring the reliability level of the structural system rather than the individual members. Therefore a structural design should be implemented based on integral structural analysis and reliability assessment [2]. However, the current limit state design for steel frames, e.g. AISC LRFD [3], is based on individual member checks, comprising the elastic integrated structural analysis for determining internal forces in the structural members and the capacity check of individual members. This approach leads to an ambiguous system reliability of the structure designed with only implementing member safety checks. The load and resistance factors design approach(LRFD), a probability-based limit state design approach, is just such a method. As an improvement, a structural design approach called preliminary integrated design(PID) [4] is constructed based on the frame analysis-frame check instead of the frame analysis-member check. Although it is a design approach oriented to system capacity limit states, PID cannot provide a check of the structural system reliability since the load and resistance factors in this approach are not obtained on the basis of the structural system reliability evaluation. However, the reliability-based integrated design approach(RID) proposed in this paper makes up the insufficiency of PID, which can ensure the structures designed to have the reliability index as close as possible to the target values.

\section{APPROACH}

\subsection{Target Reliability Index}

The target reliability index is the expected reliability index of structural design, it is an important factor in the reliability-based structural design. Theoretically, the value of target reliability index 
should be established through optimal method according to the importance of structures, failure consequences, causes and modes of structures, and economic ability. Because of the deficiency of statistical information and considering the succession of the specifications, the target reliability index used in current codes is adopted by calibrating to the safety level implied by existing codes. Similar to AISC LRFD [3], GB50068-2001 [5] is also a probabilistic design code based on the limit states of structural components, and its target safety level, as shown in Table 1 ( $\beta$ denotes reliability index, $\mathrm{P}_{\mathrm{f}}$ denotes failure probability), is taken to be the probabilities of structural failure implied by given codes which are judged to be acceptable in China. For the sake of simplification and conservative consideration, it is reasonable that the target reliability index used in RID can has a increase of 0.5 compared to the target reliability index employed in the limit state design approach based on individual members with ductile failure mode, because although the integrated failure of steel frames is ductile, its importance level is comparative to that of component failure of structures with brittle mode, so the target reliability index of the former is the same as the latter.

Table 1. Target reliability index employed in current specification and RID

\begin{tabular}{cccccccc}
\hline \hline \multirow{2}{*}{ Design method } & \multirow{2}{*}{ Failure mode } & \multicolumn{2}{c}{ Class 1 } & \multicolumn{2}{c}{ Class 2 } & \multicolumn{2}{c}{ Class 3 } \\
& & $\beta$ & $\mathrm{P}_{\mathrm{f}}$ & $\beta$ & $\mathrm{P}_{\mathrm{f}}$ & $\beta$ & $\mathrm{P}_{\mathrm{f}}$ \\
\hline Current & Brittle failure & 4.2 & $1.3 \times 10^{-5}$ & 3.7 & $1.1 \times 10^{-4}$ & 3.2 & $6.9 \times 10^{-4}$ \\
specification & Ductile failure & 3.7 & $1.1 \times 10^{-4}$ & 3.2 & $6.9 \times 10^{-4}$ & 2.7 & $3.5 \times 10^{-3}$ \\
\hline RID & Ductile failure & 4.2 & $1.3 \times 10^{-5}$ & 3.7 & $1.1 \times 10^{-4}$ & 3.2 & $6.9 \times 10^{-4}$ \\
\hline \hline
\end{tabular}

\subsection{Load and Load Combination}

Three types of loads need to be considered in the reliability-based integrated design of steel frames. They are dead load, live load and wind load. The statistic data of these loads are tabulated in Table 2. Two loading cases are investigated. One is vertical dead load with vertical live load and the other is vertical dead load with simultaneously vertical live load and horizontal wind load. In assessment of system reliability, dead load and live load are treated as random load in loading case 1 while only wind load is treated as random load in loading case 2.

Table 2. Statistic data of various loads

\begin{tabular}{l|l|l|l}
\hline & $\begin{array}{l}\text { Ratio of mean to } \\
\text { normal value }(\mathrm{K})\end{array}$ & Coefficient of variance(COV) & Distribution type \\
\hline Dead load & 1.06 & 0.07 & Normal \\
Live load & 1.00 & 0.25 & Gumbel \\
Wind load & 0.999 & 0.193 & Gumbel \\
\hline \hline
\end{tabular}

\subsection{Statistics of Structural Resistance}

The randomness of structural resistance of steel frames is mainly relevant to the randomness of the sectional geometry, the randomness of material yielding strength and the randomness of calculation mode for determining structural resistance, the statistics of which are listed in Table 3 [6].

It is observed that the PDF curves of structural resistance of steel frames under the two loading cases fit lognormal distribution quite well [7]. Therefore, the structural integrated resistance of steel frames will be assumed to follow a lognormal distribution in the following calculation of load and resistance factors. 
Table 3. Statistics of principal random variables influencing structural resistance

\begin{tabular}{|c|c|c|c|c|}
\hline & & & $\begin{array}{l}\text { Ratio of mean } \\
\text { to normal value }\end{array}$ & Coefficient of variance \\
\hline Geometrical parameters & $\begin{array}{l}\text { Length } \\
\text { thickn }\end{array}$ & idth & $\begin{array}{l}1.000 \\
1.000 \\
\end{array}$ & $\begin{array}{l}0.0135 \\
0.0350\end{array}$ \\
\hline \multirow{2}{*}{$\begin{array}{l}\text { Yielding strength of } \\
\text { steel }\end{array}$} & Q235 & $\begin{array}{l}\mathrm{t} \leqslant 16 \mathrm{~mm} \\
16 \mathrm{~mm}<\mathrm{t} \leqslant 40 \mathrm{~mm} \\
40 \mathrm{~mm}<\mathrm{t} \leqslant 60 \mathrm{~mm} \\
60 \mathrm{~mm}<\mathrm{t} \leqslant 100 \mathrm{~mm}\end{array}$ & $\begin{array}{l}1.070 \\
1.074 \\
1.118 \\
1.087\end{array}$ & $\begin{array}{l}0.081 \\
0.077 \\
0.066 \\
0.066\end{array}$ \\
\hline & Q345 & $\begin{array}{l}\mathrm{t} \leqslant 16 \mathrm{~mm} \\
16 \mathrm{~mm}<\mathrm{t} \leqslant 35 \mathrm{~mm} \\
35 \mathrm{~mm}<\mathrm{t} \leqslant 50 \mathrm{~mm} \\
50 \mathrm{~mm}<\mathrm{t} \leqslant 100 \mathrm{~mm}\end{array}$ & $\begin{array}{l}1.040 \\
1.025 \\
1.125 \\
1.184 \\
\end{array}$ & $\begin{array}{l}0.066 \\
0.076 \\
0.057 \\
0.083\end{array}$ \\
\hline $\begin{array}{lrr}\text { Calculation } & \text { mode } & \text { for } \\
\text { determining } & \text { structural } \\
\text { resistance } & & \end{array}$ & \multicolumn{2}{|c|}{$\begin{array}{l}\text { Vertical load } \\
\text { Horizontal and vertical load }\end{array}$} & $\begin{array}{l}1.000 \\
1.000\end{array}$ & $\begin{array}{l}0.075 \\
0.075\end{array}$ \\
\hline
\end{tabular}

\subsection{Practical Design Formula}

Reliability-based integrated design method for steel portal frames is first introduced in [4]. The practical design formula of this method can be written as

$$
R_{n} / \phi \geq \gamma_{0} \cdot \sum \gamma_{i} \cdot S_{n i}
$$

where $R_{n}$ is the nominal value of structural resistance determined by nonlinear structural analysis, $S_{n i}$ is a load effect, $\phi$ and $\gamma_{i}$ are the factors of structural resistance and load effect, which can be obtained by reliability analysis of structures, $i$ stands for the number of load effects, and $\gamma_{0}$ is the importance factor of structures. Though Eq.(1) is similar to that of traditional LRFD, they factually differ from each other because the factors of resistance and load in RID are based on ensuring reliability of structural system, rather than reliability of individual members as in LRFD.

\subsubsection{Importance Factor}

The value of importance factor $\gamma_{0}$ used in conventional member-checked approach is taken as

1. for structure components whose importance class is class one or serviceable life is more than 100 years, $\gamma_{0}$ should not be less than 1.1 ;

2. for structure components whose importance class is class two or serviceable life is 50 years, $\gamma_{0}$ should not be less than 1.0 ;

3. for structure components whose importance class is class three or serviceable life is 5 years, $\gamma_{0}$ should not be less than 0.9 .

Since $\gamma_{0}$ is only relevant to the importance of structures, the importance factor of structures employed in RID can take the same value as in LRFD, stated as above.

\subsubsection{Load and Resistance Factors}

The process of determining the load and resistance factors in the formula for RID is similar to that for traditional limit-state design, except that the factors of the former come from assessment of system reliability of structures whereas those of the latter from reliability calibration of individual members [2]. The flow chart for determining load and resistance factors for RID is given in 
Figure 1 and the data used for this purpose are listed in Table 4, the values of resistance statistics in Table 4 are taken from the sampling of the structural resistance which is calculated by finite element program.

Table 4. Data used in calculation of load and resistance factors

(a) Q235

\begin{tabular}{lllllll}
\hline \hline Load case & Resistance factor Load factor & & \multicolumn{2}{l}{ Load ratio } & \multicolumn{2}{l}{ Resistance statistics } \\
\hline 1 & 1.20 & Dead load & Live load & Live load/ dead load & COV & $\mathrm{K}_{\mathrm{R}}{ }^{3)}$ \\
& & $1.00-1.60^{1)}$ & $1.40-3.00^{1)}$ & $0.50-1.10^{2)}$ & 0.110 & 1.035 \\
2 & \multirow{2}{*}{1.20} & Dead load+live load & Wind load & none & COV & $\mathrm{K}_{\mathrm{R}}{ }^{3)}$ \\
& 1.0 & $1.10-2.65^{1)}$ & none & 0.108 & 1.065 \\
\hline \hline
\end{tabular}

(b) Q345

\begin{tabular}{|c|c|c|c|c|c|c|}
\hline \multirow{3}{*}{$\frac{\text { Load case }}{1}$} & \multicolumn{3}{|c|}{ Resistance factor Load factor } & \multirow{3}{*}{$\begin{array}{l}\text { Load ratio } \\
\text { Live load/ dead load } \\
0.50-1.10^{2)}\end{array}$} & \multicolumn{2}{|c|}{ Resistance statistics } \\
\hline & 1.20 & Dead load & Live load & & $\mathrm{COV}$ & $\mathrm{K}_{\mathrm{R}}^{3)}$ \\
\hline & & $1.00-1.60^{1)}$ & $1.40-3.00^{1)}$ & & 0.110 & 1.046 \\
\hline 2 & 1.20 & Dead load + live load ${ }^{4)}$ & Wind load & none & $\mathrm{COV}$ & $\mathrm{K}_{\mathrm{R}}^{3)}$ \\
\hline & & 1.0 & $1.10-2.65^{1)}$ & none & 0.121 & 1.103 \\
\hline
\end{tabular}

1) Interval is equal to 0.05 ;

2) Interval is equal to 0.15 ;

3) $\mathrm{K}_{\mathrm{R}}$ is the ratio of mean to normal value of structure resistance;

4) The summation of dead load and live load is treated as a constant load in load case 2.

For the convenience of practical application, the resistance factor, $\phi$, can be taken as a constant being equal to 1.2, and the optimal load factors can then be determined according to the target reliability with this strategy. Following the process of calculation shown in Figure 1, the load and resistance factors with a certain system reliability for reliability-based integrated design of steel frames can be determined. The relative errors between $R_{K i j}$ and $R_{K j}^{*}$ indicated in Figure 1 under different load factors and different target reliability index is shown in Figure 2. The optimal load and resistance factors for RID aiming at definite target reliability levels are listed in Table 5.

Since the final values of resistance factors are very close to the initial value 1.2 , it is acceptable that uniform resistance factor for RID, $\phi=1.2$, can be employed in the practical application.

Table 5. Optimal load and resistance factors and their errors

(a) Q235

\begin{tabular}{ccccccc}
\hline \hline \multirow{2}{*}{$\beta_{\mathrm{t}}$} & \multicolumn{3}{c}{ Load case 1 } & \multicolumn{3}{c}{ Load case 2 } \\
& $\gamma_{\mathrm{G}}$ & $\gamma_{\mathrm{L}}$ & $\gamma_{\mathrm{R}}^{\prime}$ & $\varepsilon$ & $\gamma_{\mathrm{W}}\left(\gamma_{\mathrm{G}}+\gamma_{\mathrm{L}}=1.0\right)$ & $\varepsilon$ \\
\hline 2.7 & 1.10 & 1.60 & 1.1898 & $5.08398 \mathrm{e}-004$ & 1.45 & $2.53647 \mathrm{e}-004$ \\
3.2 & 1.10 & 1.90 & 1.1969 & $7.09022 \mathrm{e}-005$ & 1.70 & $1.46003 \mathrm{e}-005$ \\
3.7 & 1.10 & 2.25 & 1.2023 & $2.55264 \mathrm{e}-005$ & 1.95 & $1.61455 \mathrm{e}-007$ \\
4.2 & 1.10 & 2.70 & 1.1927 & $2.21763 \mathrm{e}-004$ & 2.25 & $9.66120 \mathrm{e}-006$ \\
\hline \hline
\end{tabular}

(b) Q345

\begin{tabular}{ccccccc}
\hline \hline \multirow{2}{*}{$\beta_{\mathrm{t}}$} & \multicolumn{4}{c}{ Load case 1 } & \multicolumn{2}{c}{ Load case 2 } \\
& $\gamma_{\mathrm{G}}$ & $\gamma_{\mathrm{L}}$ & $\gamma_{\mathrm{R}}^{\prime}$ & $\varepsilon$ & $\gamma_{\mathrm{W}}\left(\gamma_{\mathrm{G}}+\gamma_{\mathrm{L}}=1.0\right)$ & $1.07029 \mathrm{e}-005$ \\
\hline 2.7 & 1.10 & 1.55 & 1.1972 & $2.80723 \mathrm{e}-004$ & 1.45 & $8.15408 \mathrm{e}-005$ \\
3.2 & 1.10 & 1.85 & 1.2025 & $1.02353 \mathrm{e}-004$ & 1.65 & $1.22249 \mathrm{e}-004$ \\
3.7 & 1.10 & 2.20 & 1.2061 & $1.40213 \mathrm{e}-004$ & 1.90 & $5.76273 \mathrm{e}-005$ \\
4.2 & 1.10 & 2.65 & 1.1948 & $1.13074 \mathrm{e}-004$ & 2.20 & 1.004 \\
\hline \hline
\end{tabular}




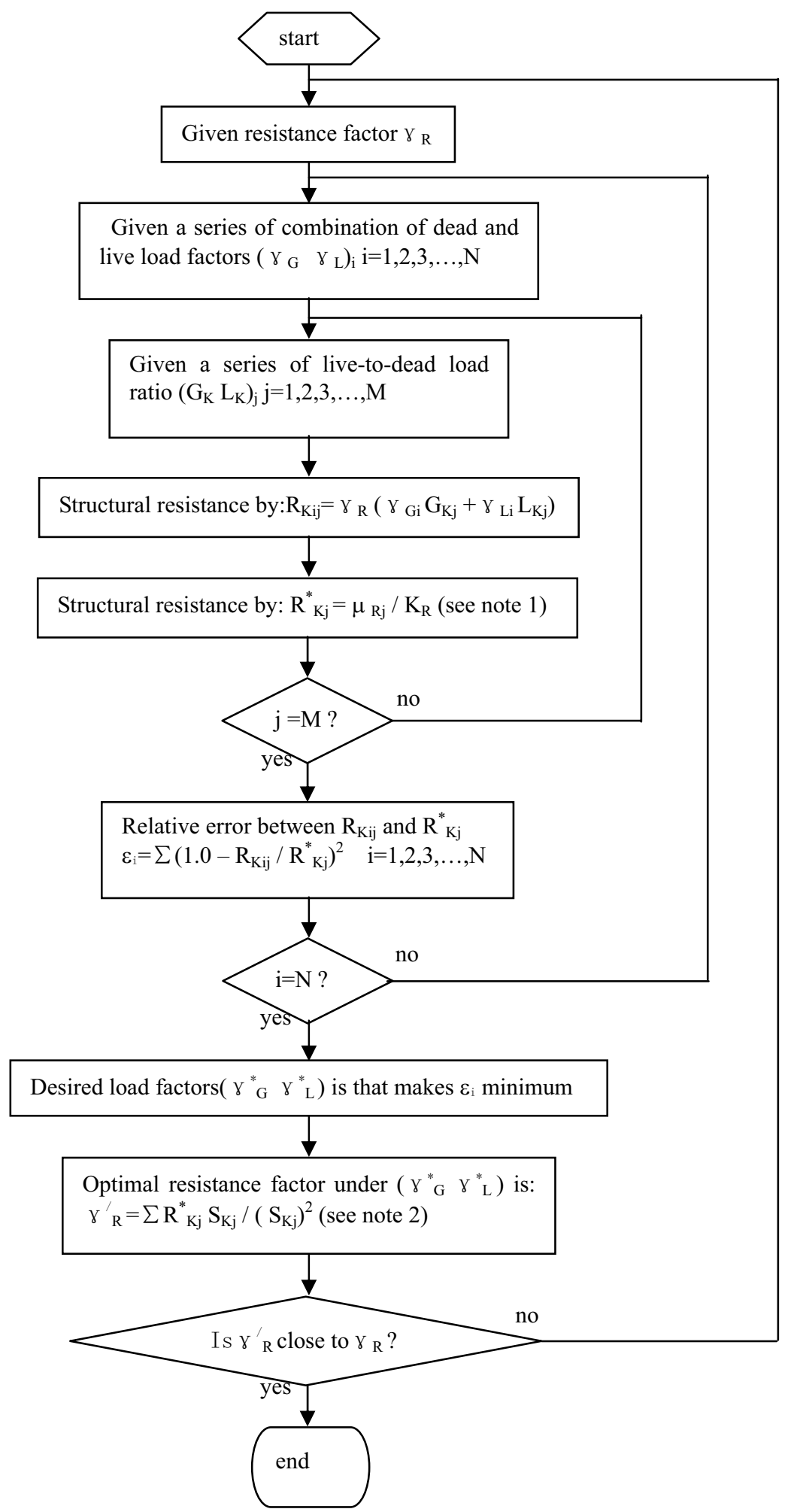

note1. $\mu_{\mathrm{Rj}}$ is determined by First Order Second Moment(FOSM) method with the statistics listed in table 4; note2. $R_{\mathrm{Kj}}$ is obtained by $R_{\mathrm{Kj}}=\gamma{ }_{\mathrm{G}} \mathrm{G}_{\mathrm{Kj}}+\gamma{ }_{\mathrm{L}} \mathrm{L}_{\mathrm{Kj}}$

Figure 1. Flow chart for calculation of load and resistance factors. 

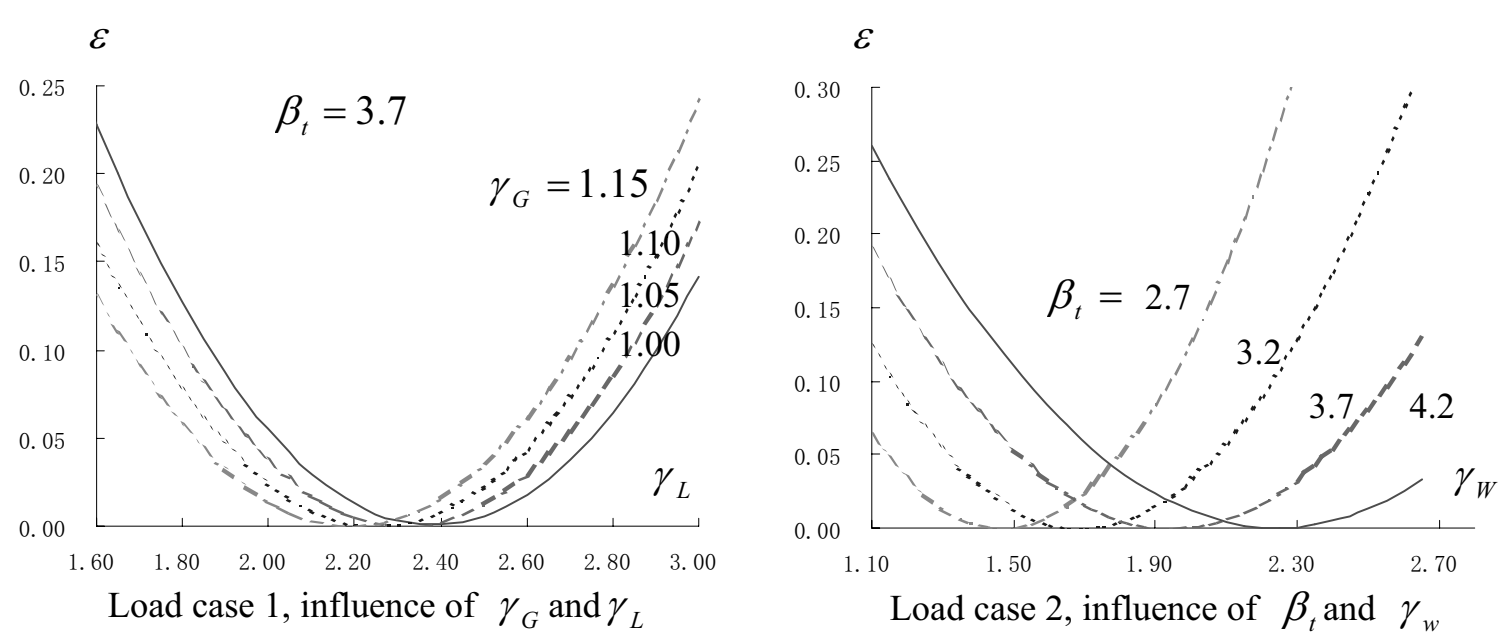

(a) Q235 steel

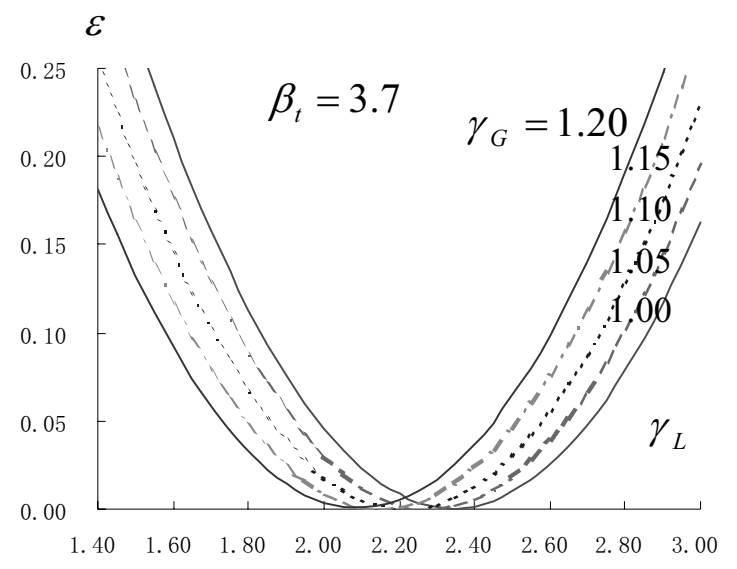

Load case 1 , influence of $\gamma_{G}$ and $\gamma_{L}$

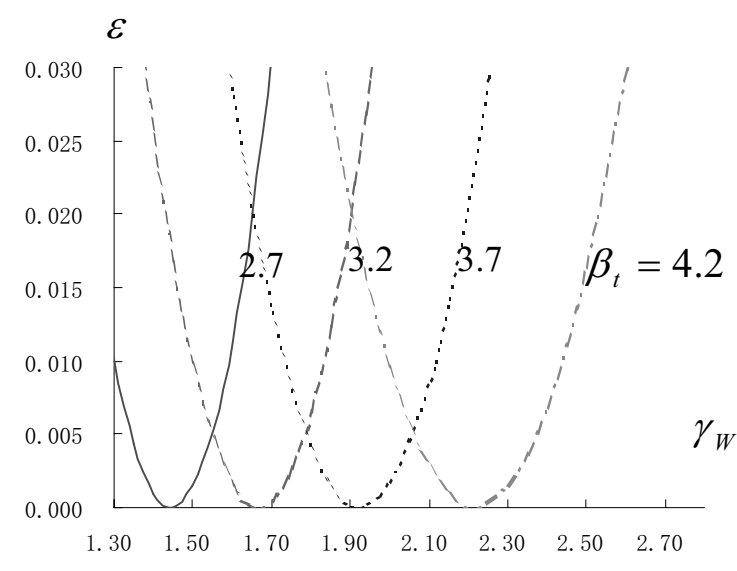

Load case 2 , influence of $\beta_{t}$ and $\gamma_{w}$

(b) Q345 steel

Figure 2. Relative error comparisons when calculating load and resistance factors

Then the expressions for design of steel frames under loading cases 1 and 2 with the target system reliability index being equals 3.7 can be obtained as

For Loading case 1, Q235 steel

$$
\begin{gathered}
R_{n} / 1.2 \geq 1.10 \cdot G_{n}+2.25 \cdot L_{n} \\
\mathrm{Q} 345 \text { steel } \\
R_{n} / 1.2 \geq 1.10 \cdot G_{n}+2.20 \cdot L_{n}
\end{gathered}
$$

where $R_{n}$ is the normal value of structure resistance under loading case 1, determined by nonlinear structural analysis; $G_{n}$ and $L_{n}$ represent the normal values of dead and live load effects.

For Loading case 2, Q235 steel

$$
\begin{aligned}
& R_{n} / 1.2\left((G+L)=1.00 \cdot\left(G_{n}+L_{n}\right)\right) \geq 1.95 \cdot W_{n} \\
& \quad \text { Q345 steel } \\
& R_{n} / 1.2\left((G+L)=1.00 \cdot\left(G_{n}+L_{n}\right)\right) \geq 1.90 \cdot W_{n}
\end{aligned}
$$

where $R_{n}$ is the normal value of structure resistance under loading case 2, determined by nonlinear structural analysis(in the process of calculation, the value of $R_{n}$ is determined under constant dead load and live load); $W_{n}$ represents the normal value of wind load. 


\subsection{Design steps}

The design steps using RID are

1. determine the structural size, material type, and the values of nominal loads of the steel frame design for;

2. select a group of sectional dimensions for the frame and perform the integrated nonlinear frame analysis, by which the nominal resistances of the trial frame $\left(R_{n}\right.$ in the design formula) under two loading cases are obtained;

3. check the design formula with the nominal frame resistances and the nominal loads;

4. repeat steps 2 and 3 till the design equations are satisfactorily met.

\section{APPLICATION}

\subsection{An Example}

An asymmetric two-storey two-bay steel frame is shown in Figure 3 [8]. Using this example, we can compare different design methods such as RID, PID and LRFD. The loads in Figure 3 is the summation of normal values of dead load and live load and the ratio of dead to live load is 1.0. The statistics used for reliability analysis is listed in Table 6 . The normal value of yielding strength of steel is $248 \mathrm{MPa}$ and the elastic modulus is $206 \mathrm{GPa}$.

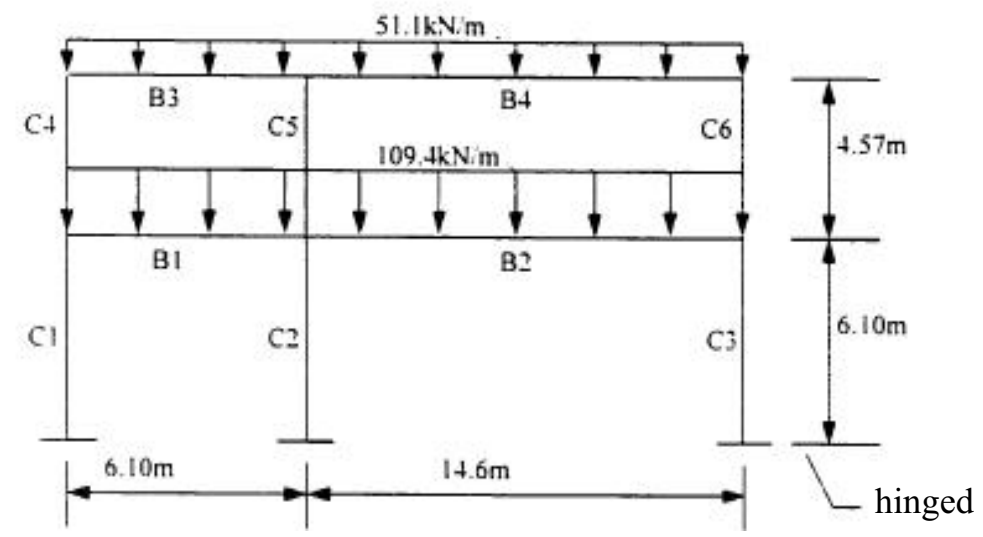

Figure 3. Dimensions and loads of a two-storey two-bay steel frame

Table 6. Statistics of loads and yielding strength of example frame [8]

\begin{tabular}{llll}
\hline \hline Statistics & $\begin{array}{l}\text { Ratio of mean to normal } \\
\text { value }\end{array}$ & $\begin{array}{l}\text { Coefficient of } \\
\text { variance }\end{array}$ & distribution \\
\hline Dead load & 1.00 & 0.08 & Normal \\
Live load & 1.00 & 0.25 & gumbel \\
Yielding strength & 1.05 & 0.10 & gumbel \\
\hline \hline
\end{tabular}

The design steps of PID are similar with those of RID. However, the load and resistance factors employed in PID are taken from LRFD, as

for loading case 1

$$
0.90 \cdot R_{n} \geq 1.20 \cdot G_{n}+1.60 \cdot L_{n}
$$


where $R_{n}$ is the nominal value of the structural resistance against vertical loads determined by nonlinear integrated structural analysis, and $G_{n}$ and $L_{n}$ are respectively the nominal value of dead and live load effects, and

for loading case 2

$$
0.90 \cdot R_{n}\left((G+L)=1.20 \cdot\left(G_{n}+L_{n}\right)\right) \geq 1.30 \cdot W_{n}
$$

where $R_{n}$ is the nominal value of the structural resistance against horizontal loads determined by nonlinear integrated structural analysis when the summation of dead load and live load is equal to 1.20 times of its nominal values, and $W_{n}$ is the nominal value of wind load.

\subsection{Design Results}

The steel frame shown in Figure 3 is designed by various methods, including traditional LRFD, PID and RID. The sections of components and the steel consumption of the frame obtained by different design methods are given in Table 7. Since for this steel frame, the loading case 1 is the control loading case, then the reliability of loading case 2 is not considered.

The results of system reliability for the frame designed by various methods are listed in Table 8 , where $\beta$ and $p_{f}$ are respectively the reliability index and failure probability.

The design results show that the system reliability index of the frame designed by LRFD is larger than the target reliability index, which is 3.7 , but the system reliability of PID is lower than that level. While the reliability index of frame designed by RID is close to the expected reliability level and meets the requirement of structural integrated design. The steel consumption of the frame designed by RID is also reasonable, which is between the values obtained respectively by LRFD and PID.

Table 7. Comparison of component sections and steel consumption obtained by various methods

\begin{tabular}{|c|c|c|c|c|}
\hline & Design method & LRFD & PID & RID \\
\hline \multirow{11}{*}{ Components } & $\mathrm{C} 1$ & $\mathrm{~W} 12 \times 19$ & $\mathrm{~W} 12 \times 14$ & $\mathrm{~W} 12 \times 16$ \\
\hline & $\mathrm{C} 2$ & $\mathrm{~W} 14 \times 132$ & $\mathrm{~W} 14 \times 99$ & $\mathrm{~W} 14 \times 109$ \\
\hline & $\mathrm{C} 3$ & $\mathrm{~W} 14 \times 109$ & $\mathrm{~W} 14 \times 82$ & $\mathrm{~W} 14 \times 99$ \\
\hline & $\mathrm{C} 4$ & $\mathrm{~W} 10 \times 12$ & $\mathrm{~W} 10 \times 12$ & $\mathrm{~W} 10 \times 12$ \\
\hline & $\mathrm{C} 5$ & $\mathrm{~W} 14 \times 109$ & $\mathrm{~W} 14 \times 99$ & $\mathrm{~W} 14 \times 109$ \\
\hline & C6 & $\mathrm{W} 14 \times 109$ & $\mathrm{~W} 14 \times 99$ & $\mathrm{~W} 14 \times 109$ \\
\hline & B1 & $\mathrm{W} 27 \times 84$ & $\mathrm{~W} 27 \times 84$ & $\mathrm{~W} 27 \times 84$ \\
\hline & B2 & $\mathrm{W} 36 \times 135$ & $\mathrm{~W} 30 \times 108$ & $\mathrm{~W} 30 \times 108$ \\
\hline & B3 & $\mathrm{W} 18 \times 40$ & $\mathrm{~W} 18 \times 40$ & $\mathrm{~W} 18 \times 40$ \\
\hline & B4 & $\mathrm{W} 27 \times 94$ & $\mathrm{~W} 27 \times 84$ & $\mathrm{~W} 27 \times 94$ \\
\hline & $\begin{array}{l}\text { Steel consumption } \\
\left(10^{3} \mathrm{~kg}\right)\end{array}$ & 9.59 & 8.51 & 9.12 \\
\hline
\end{tabular}


Table 8. System reliability of the frame designed by LRFD, PID and RID

\begin{tabular}{crc}
\hline \hline Design method & $\beta$ & $p_{f}$ \\
\hline LRFD & 4.4591 & $4.1148 \mathrm{e}-006$ \\
PID & 3.2033 & $6.7923 \mathrm{e}-004$ \\
RID & 3.8427 & $6.0856 \mathrm{e}-005$ \\
\hline \hline
\end{tabular}

\section{CONCLUSIONS}

The Reliability-based Integrated Design (RID) of planar steel frames is studied in this paper. The following conclusions can be drawn from above studies:

1). The system reliability index of steel frames designed by RID is larger than that designed by PID and lower than that designed by LRFD, while it is close to the expected reliability level and meets the requirement of structural integrated design.

2). Although it is also an integrated design method, PID cannot provide a check of the system reliability level since the load and resistance factors in its design expressions are coming directly from LRFD without consideration of system reliability. So the system reliability of a structure designed by PID cannot be guaranteed.

3). From the example concerning design of a steel frame, it can be seen that RID consumes less steel than LRFD. This novel design method can make up the insufficiency of conventional design method and facilitate the design procedure without requirement of member checks, while ensuring system reliability.

\section{REFERENCES}

[1] Ellingwood, B.R., "Probability-based codified design: past accomplishments and future challenges", Structural Safety, 1994, 13, pp.159-176.

[2] Li, J-H., "Probabilistic limit-state design for building structures", Beijing, Press of Chinese Construction Industry, 1990 (in Chinese).

[3] AISC LRFD, "Manual of steel construction, load and resistance factor design", 2nd edition, Chicago (IL): American Institute of Steel Construction, 1994.

[4] Li, J-J. and Li, G-Q, "Reliability-based integrated design of steel portal frames with tapered members", Structural Safety, 2004, 26, pp.221-239

[5] GB 50068-2001, "The reliability design uniform standard for building structures", 2001 (in Chinese).

[6] Zhang, X-P., "Reliability analysis and design for building structures", Beijing, Science Press, 2001 (in Chinese).

[7] Liu, Y-S, "Research on theory of nonlinear analysis and integrated reliability design for planar steel frames", PhD dissertation, Tongji University, Shanghai, PR China, 2004 (in Chinese).

[8] Zhou, W-X, "Reliability evaluations of reinforced concrete columns and steel frames", Ph.D dissertation, University of Western Ontario, 2000. 